\title{
Adolescent Cocaine Exposure Causes Enduring Macroscale Changes in Mouse Brain Structure
}

\author{
Anne L. Wheeler, ${ }^{1,2}$ Jason P. Lerch, ${ }^{1,3,4}$ M. Mallar Chakravarty, ${ }^{5,6,7}$ Miriam Friedel, ${ }^{1,3}$ John G. Sled, ${ }^{1,3,4}$ Paul J. Fletcher, \\ Sheena A. Josselyn, ${ }^{1,2,9,10}$ and Paul W. Frankland ${ }^{1,2,9,10}$ \\ ${ }^{1}$ Program in Neurosciences and Mental Health, The Hospital for Sick Children, Toronto, Canada, M5G 1X8, ${ }^{2}$ Institute of Medical Science, University of \\ Toronto, Toronto, Canada, M5S 1A8, ${ }^{3}$ Mouse Imaging Centre, The Hospital for Sick Children, Toronto Centre for Phenogenomics, Toronto, Canada, M5T \\ 3H7, ${ }^{4}$ Department of Medical Biophysics, University of Toronto, Toronto, Canada, M5G 2M9, ${ }^{5}$ Kimel Family Translational Imaging Genetics Laboratory, \\ Research Imaging Centre, Centre for Addiction and Mental Health, Toronto, Canada, M5T 1R8, ${ }^{6}$ Department of Psychiatry, University of Toronto, Toronto, \\ Canada, M5T 1R8, ${ }^{7}$ Rotman Research Institute, Baycrest, Toronto, Canada, M6A 2E1, ${ }^{8}$ Biopsychology Section, Neuroscience Research Department, Centre \\ for Addiction and Mental Health, Toronto, Canada, M5T 1R8, ${ }^{9}$ Department of Psychology, University of Toronto, Toronto, Canada, M5S 3G3, and \\ ${ }^{10}$ Department of Physiology, University of Toronto, Toronto, Canada M5S 1A8
}

Cocaine dependence is associated with abnormalities in brain structure in humans. However, it is unclear whether these differences in brain structure predispose an individual to drug use or are a result of cocaine's action on the brain. This study investigates the impact of chronic cocaine exposure on brain structure and drug-related behavior in mice. Specifically, mice received daily cocaine or saline injections for $20 \mathrm{~d}$ during two developmental time periods: adolescence ( $27-46 \mathrm{~d}$ old $)$ and young adulthood ( $60-79 \mathrm{~d}$ old). Following $30 \mathrm{~d}$ of abstinence, either fixed brain T2 weighted magnetic resonance images were acquired on a $7 \mathrm{~T}$ scanner at $32 \mu \mathrm{m}$ isotropic voxel dimensions or mice were assessed for sensitization to the locomotor stimulant effects of cocaine. Three automated techniques (deformation-based morphometry, striatum shape analysis, and cortical thickness assessment) were used to identify population differences in brain structure in cocaine-exposed versus saline-exposed mice. We found that cocaine induced changes in brain structure, and these were most pronounced in mice exposed to cocaine during adolescence. Many of these changes occurred in brain regions previously implicated in addiction including the nucleus accumbens, striatum, insular cortex, orbitofrontal cortex, and medial forebrain bundle. Furthermore, exposure to the same cocaine regimen caused sensitization to the locomotor stimulant effects of cocaine, and these effects were again more pronounced in mice exposed to cocaine during adolescence. These results suggest that altered brain structure following 1 month of abstinence may contribute to these persistent drug-related behaviors, and identify cocaine exposure as the cause of these morphological changes.

\section{Introduction}

Cocaine is a psychostimulant drug that acts acutely by inhibiting monoamine reuptake at synapses in the brain, producing a feeling of euphoria (Gawin, 1991). However, repeated cocaine use can cause persistent alterations in brain regions important for reward and learning (Nestler, 2005; Thomas et al., 2008), leading to a long-lasting psychological dependence with detrimental effects for the addicts, those close to them, and society.

Previous magnetic resonance imaging (MRI) studies have shown that cocaine dependence is associated with structural abnormalities in the brain, predominantly in the frontal cortex and temporal lobe (Bartzokis et al., 2000; Franklin et al., 2002; Sim et

Received Aug. 8, 2012; revised Nov. 7, 2012; accepted Nov. 21, 2012.

Author contributions: A.L.W., J.P.L., J.G.S., P.J.F., S.A.J., and P.W.F. designed research; A.L.W. performed research; A.L.W., M.M.C., and M.F. analyzed data; A.L.W. and P.W.F. wrote the paper.

This work was supported by a grant from the Canadian Institutes of Health Research and the Ontario Mental Health Foundation to P.W.F. (MOP-77561). A.L.W. received support from the Ontario Mental Health Foundation.

Correspondence should be addressed to Paul Frankland, Program in Neurosciences and Mental Health, The Hospital for Sick Children, 555 University Avenue, Toronto, Canada, M5G 1X8. E-mail: paul.frankland@sickkids.ca. DOI:10.1523/JNEUROSCI.3830-12.2013

Copyright $\odot 2013$ the authors $\quad 0270-6474 / 13 / 331797-07 \$ 15.00 / 0$ al., 2007; Makris et al., 2008; Ersche et al., 2011). While, in some cases, structural differences may predate onset of cocaine use and therefore predispose an individual toward cocaine dependence (Ersche et al., 2012), other structural differences likely reflect the impact of repeated cocaine use on the brain. However, isolating the impact of cocaine on brain structure in human imaging studies can be challenging. First, alcohol, nicotine, and caffeine consumption are characteristic of chronic drug users (Compton et al., 2007) and so concurrent drug use or other lifestyle factors may contribute to structural variability in the brain. Second, comorbid diagnoses of mood, anxiety, and disruptive behavior disorders are common in cocaine-dependent subjects (Swendsen et al., 2010), making it difficult to attribute morphological differences to cocaine use specifically. Third, typically there is variability in subjects' history of cocaine exposure (e.g., pattern and duration of cocaine use, drug quality, route of administration, periods of abstinence, and total lifetime intake) and in the accuracy of self-reports concerning these factors.

Experimental animal models allow for careful control of drug exposure and therefore may be used to study the impact of cocaine exposure on brain structure under controlled conditions. 
Indeed, previous studies have used animal models to investigate cocaine-related changes in brain structure at the microscopic level, focusing, for example, on changes in neuronal morphology in reward-related brain regions (Robinson and Kolb, 2004). Similar to the human imaging studies, here we used high-resolution mouse MRI to comprehensively map cocaine-associated changes in brain structure at the macroscopic level (Nieman et al., 2007). As drug use is often initiated during adolescence-a time point where the brain is still developing (Giedd, 2008; Casey and Jones, 2010) and therefore thought to be particularly vulnerable to druginduced alterations in structure and function-we compared the impact of cocaine exposure in adolescent and young adult mice. Accordingly, mice were exposed to cocaine (or saline) daily for $20 \mathrm{~d}$ followed by a $30 \mathrm{~d}$ period of drug abstinence and then either structure of the whole brain was assessed with MRI or the mice were tested for cocaine locomotor sensitization to provide a functional measure of the effects of chronic cocaine exposure.

\section{Materials and Methods}

Mice

Male offspring from a cross between C57BL/6NTacfBr (C57B6) and 129Svev (129) mice (Taconic) were used in all experiments. All mice were bred in our colony at The Hospital for Sick Children. Mice were weaned on postnatal day (PND) 21, group housed (3-5 mice per cage), and maintained on a $12 \mathrm{~h}$ light/dark cycle with ad libitum access to food and water. In these studies we used both adolescent (PND 27) and young adult (PND 60) mice. PND27 was chosen as this age coincides with the start of puberty and growth spurt, and is associated with the onset of adolescent-typical behaviors including increased sociability, risk taking, and novelty seeking (Spear, 2000). Behavioral procedures were conducted during the light phase of the cycle. Experiments were conducted according to protocols approved by the Animal Care Committee at The Hospital for Sick Children.

\section{Cocaine administration}

Cocaine hydrochloride (Medisca Pharmaceutique) was dissolved in saline and injected intraperitoneally. Adolescent and young adult mice received daily injections of cocaine $(20 \mathrm{mg} / \mathrm{kg})$ or saline for 20 consecutive days (adolescent: PND 27-46; adult: PND 60-79). This dose was chosen because it falls within the range of doses (15-30 mg/kg per day) that cause persistent increases in dendritic branching and spine density in the nucleus accumbens and prefrontal cortex of rodents (Robinson and Kolb, 2004; Pulipparacharuvil et al., 2008). Following 30 d of abstinence, mouse brains were either fixed for MRI or behavioral sensitization was tested. Imaging and testing occurred at a time when both groups were considered adults (adolescent exposure: PND 77; adult exposure: PND 110) to examine the long-term impact of cocaine exposure during the adolescent and young adult period.

\section{MRI}

Brain preparation. Mice (adolescent cocaine exposure, $n=7$; adolescent saline exposure, $n=8$; adult cocaine exposure, $n=9$; adult saline exposure, $n=8)$ were deeply anesthetized with chloral hydrate $(400 \mathrm{mg} / \mathrm{kg}$, i.p.), and perfused through the heart with PBS followed by paraformaldehyde $\left(4 \% \mathrm{PFA}, 4^{\circ} \mathrm{C}\right)$. Bodies, along with the skin, lower jaw, ears, and the cartilaginous nose tip were removed. The remaining skull structures containing the brain were allowed to postfix in $4 \% \mathrm{PFA}$ at $4^{\circ} \mathrm{C}$ for $12 \mathrm{~h}$. Following a washout period of $5 \mathrm{~d}$ in PBS and $0.01 \%$ sodium azide at $15^{\circ} \mathrm{C}$, the skulls were transferred to a PBS and 2 mм ProHance (Bracco Diagnostics Inc.) solution for at least $7 \mathrm{~d}$ at $15^{\circ} \mathrm{C}$ before imaging.

MR acquisition. A multichannel 7.0 T MRI scanner (Varian) with a $6 \mathrm{~cm}$ inner bore diameter insert gradient was used to acquire anatomical images of brains. Brains were imaged within skulls to minimize geometric distortion. Before imaging, the samples were removed from the contrast agent solution, blotted, and placed into plastic tubes $(13 \mathrm{~mm}$ in diameter) filled with a proton-free susceptibility-matching fluid (Fluorinert FC-77; $3 \mathrm{M}$ ). Three custom-built, solenoid coils (14 mm in diameter, $18.3 \mathrm{~cm}$ in length) with over wound ends were used to image three brains in parallel. Parameters used in the scans were optimized for gray/white matter contrast: a T2weighted, 3D fast spin-echo sequence with 6 echoes, with TR/TE $=325 / 32$ $\mathrm{ms}$, four averages, field-of-view $14 \times 14 \times 25 \mathrm{~mm}^{3}$, and matrix size $=432 \times$ $432 \times 780$ giving an image with $32 \mu \mathrm{m}$ isotropic voxels. Geometric distortion due to position of the three coils inside the magnet was calibrated using a precision machined MR phantom.

Volume analysis. We used an image registration-based approach to assess anatomical differences related to cocaine exposure. Image registration finds a smooth spatial transformation that best aligns one image to another such that corresponding anatomical features are superimposed. We used an automated intensity-based groupwise registration approach (Lerch et al., 2011) to align all brains in the study into a common coordinate system, yielding an average image of the 32 MRI scans. The deformation that brings the images into alignment becomes a summary of how they differ. To assess volume differences between groups deformation-based morphometry was used as it provides a continuous voxel by voxel definition of volume changes (expansion/contraction) related to drug and age of exposure. Deformations were mapped from the individual scans back to the average image. The final deformation fields were computed with a greedy symmetric diffeomorphic registration (the SyN algorithm in ANTS; Avants et al., 2008; Klein et al., 2009), then inverted and blurred with a $100 \mu \mathrm{m}$ Gaussian smoothing kernel. The Jacobian determinants of these deformations were extracted, giving a measure of local volume expansion/contraction at every voxel in the brain (Chung et al., 2001). Log-transformed Jacobian determinants were used to assess differences between groups because they better estimate a normal distribution (Leow et al., 2007). In this analysis individual voxel measurements were assessed by comparing the log-transformed Jacobian determinants at each voxel across the brain in the four groups with a two-way ANOVA. Cocaine-treated and saline-treated groups were subsequently compared at each age of exposure using a $t$ statistic. Multiple comparisons were controlled for using the False Discovery Rate (FDR; Genovese et al., 2002).

Striatum shape analysis. Changes in striatum shape and size may be described by computing inward and outward displacement of the surface of the structure (Lerch et al., 2008b). Accordingly, a pre-existing expertsegmented MRI atlas with striatum labels (Dorr et al., 2008) was warped to match the population average of the mice imaged in this study. A surface representation of the striatum was generated from the final nonlinear atlas. The dot product of the surface normal of the atlas striatum with the inverted deformation field from each mouse was calculated to estimate the inward and outward displacement of the surface at each vertex of the striatum. These displacement values were then blurred along the surface using a $300 \mu \mathrm{m}$ diffusion smoothing kernel (Chung et al., 2003). The displacement distances were analyzed for group differences with a two-way ANOVA followed by $t$ tests to compare saline and cocaine exposure at each age. Multiple comparisons were controlled for using the FDR.

Cortical thickness analysis. Cortical thickness was assessed as previously described (Lerch et al., 2008a). Briefly, cortical labels were transformed to each mouse brain that defined the cortex boundaries and stored them on a rasterized grid. Laplace's equation was used to create streamlines between the inside and outside cortical surfaces and the length of these streamlines was used to measure cortical thickness. A surface coordinate system was mapped to each subject to compare cortical thickness across groups of mice. The thickness of each of the 18,000 vertices was related to drug and age of drug exposure with a two-way ANOVA. Cocaine-treated and saline-treated groups were subsequently compared at each age of exposure using a $t$ statistic. Multiple comparisons were controlled for using the FDR.

\section{Behavioral sensitization}

Locomotor sensitization was assessed in a dimly lit square-shaped Plexiglas arena $(45 \times 45 \times 20 \mathrm{~cm}$ height). Locomotion was tracked by a camera located above the arena, and total distance traveled computed with Limelight2 (Actimetrics). Mice (adolescent cocaine exposure, $n=9$; adolescent saline exposure, $n=7$; adult cocaine exposure, $n=7$; adult saline exposure, $n=7$ ) were initially habituated to the arena for $45 \mathrm{~min}$ on $2 \mathrm{~d}$ before cocaine/saline exposure. To habituate mice to the injection procedure, all mice received an injection of saline before being placed in 

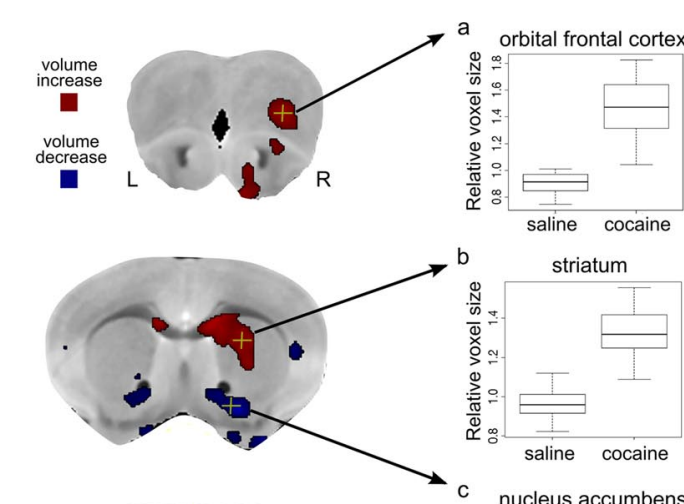

nucleus accumbens
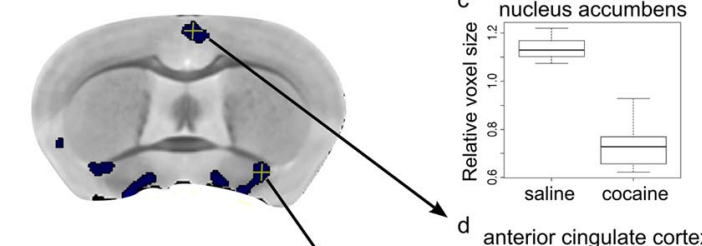

d

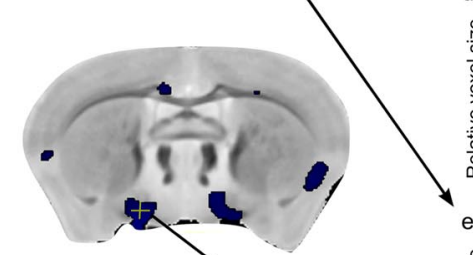

cingulate cortex 每

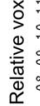
$\frac{\pi}{\square}$

e

$\stackrel{N}{N}$
$\frac{N}{0}$
D
Oे

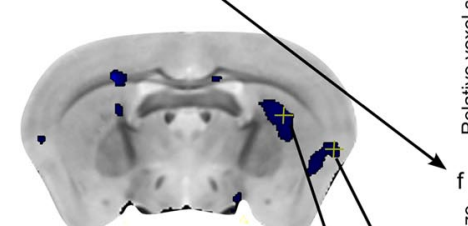

$f$

$f$ medial forebrain bundle
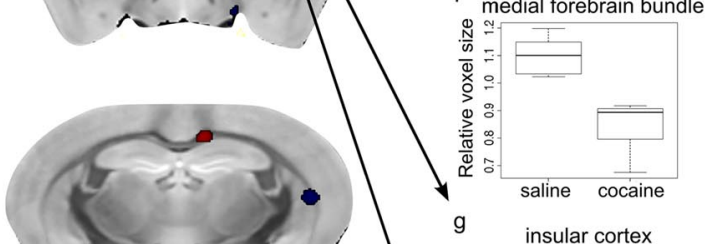

g

离

insular cortex
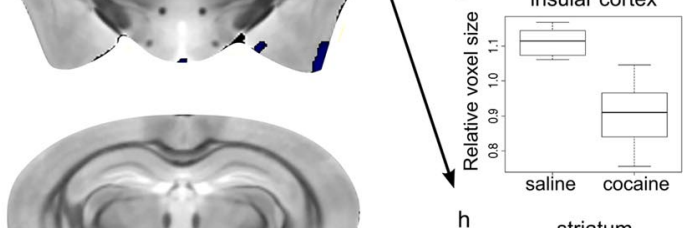

$h$
$\frac{N}{\omega}$
$\frac{N}{d}$
$\frac{0}{x}$
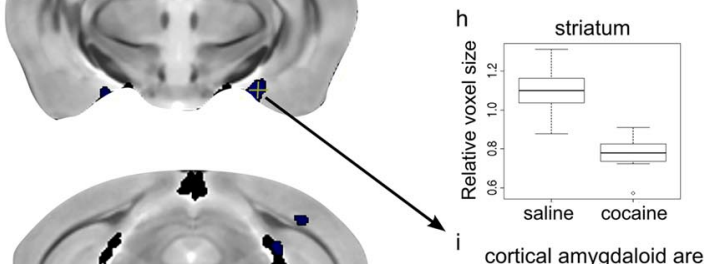

saline cocaine

cortical amygdaloid area
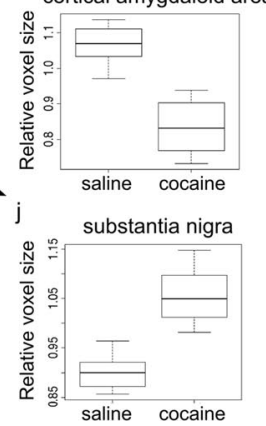

Figure 1. Coronal slices showing the localization of voxelwise differences between mice treated with cocaine versus saline during adolescence. Slices arranged from anterior (top) to
Table 1. Regional changes in mice exposed to cocaine during adolescence

\begin{tabular}{lll}
\hline Brain region & Direction & Hemisphere \\
\hline Orbital frontal cortex & Increase & Right \\
Striatum (anterior) & Increase & Right \\
Striatum (posterior) & Decease & Bilateral \\
Nucleus accumbens & Decease & Bilateral \\
Anterior cingulate cortex & Decrease & Bilateral \\
Ventral pallidum & Decrease & Bilateral \\
Medial forebrain bundle & Decrease & Bilateral \\
Insular cortex & Decrease & Bilateral \\
Cortical amygdaloid area & Decrease & Bilateral \\
Substantia nigra & Increase & Bilateral \\
Anterior olfactory area & Increase & Right \\
Corpus callosum & Increase & Bilateral \\
Rhinal cortex & Decrease & Bilateral \\
Piriform cortex & Decrease & Right \\
Medulla & Increase & Bilateral
\end{tabular}

Brain regions where volumetric differences were observed following cocaine exposure during adolescence. Direction of change refers to cocaine exposed mice relative to saline exposed mice. Changes were observed at the voxel level after correcting for multiple comparisons with 5\% FDR correction. See Figure 1 for visualization of these data.

the chamber on the second habituation day. The mice then received 20 consecutive daily injections of cocaine or saline. On days 1,2, and 20 of cocaine/saline exposure, locomotor activity was assessed in the arena for $45 \mathrm{~min}$ following injection. On the 17 remaining drug-exposure days, mice were returned to their homecage following cocaine/saline injection. Following cocaine/saline exposure, mice then remained in their homecage, undisturbed for 28 drug-free days. All mice, regardless of drug-exposure group, were tested identically. Locomotor testing consisted of three testing sessions on consecutive days where mice were placed in the arena for $45 \mathrm{~min}$ following injection. On test days $1-3$ mice were injected with saline, $10 \mathrm{mg} / \mathrm{kg}$ cocaine, and $20 \mathrm{mg} / \mathrm{kg}$ cocaine, respectively. For each test, data were analyzed using a three-way ANOVA with age of exposure (adult or adolescent) and drug pre-exposure (cocaine or saline) as between-subject variables and time $(0-15,16-30$, and $31-45 \mathrm{~min})$ as a within-subject variable. Significant main effects and interactions were followed up by two-way ANOVAs within test time intervals with age of exposure and drug pre-exposure as betweensubject variables and $t$ tests to compare the effect of drug pre-exposure in each age group.

\section{Results \\ MRI}

Volume analysis provided an assessment of voxel level volumetric change across the entire brain allowing for the precise localization of cocaine-induced alterations within brain structures. We observed significant interactions between age of exposure and drug in several brain regions. Subsequent direct comparison of cocaine-exposed versus saline-exposed mice in each age group indicated that these interactions were primarily driven by structural changes in mice exposed to cocaine during adolescence. Strikingly, many of these volumetric alterations were localized to brain regions previously implicated in reward processing and addiction (Fig. 1; Table 1). For example, there were robust, bilateral volumetric reductions in the nucleus accumbens [(Fig. $1 c$. Two-way ANOVA: drug by age interaction $F_{(1,28)}=55.75 p<$

$\leftarrow$

posterior (bottom). These maps show voxels where there was an interaction between age and drug $(t>10.95,5 \%$ FDR) and a difference between cocaine and saline exposure during adolescence ( $t>3.98,5 \%$ FDR). Colors indicate regions where cocaine-exposed mice showed increased (red) and decreased (blue) volume relative to saline exposed mice. L, Left hemisphere; $R$, right hemisphere. Relative voxel size in the adolescent-exposed mice at selected highlighted voxels (yellow crosshairs) are displayed in the box plots to the right $(\boldsymbol{a}-\boldsymbol{j})$ where the midline represents the median of the data, the box shows the first and third quartiles, and the vertical line represents the range. There were no significant differences between animals exposed to saline and cocaine during adulthood. 
a

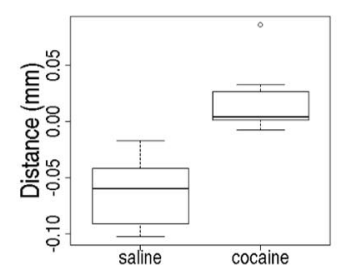

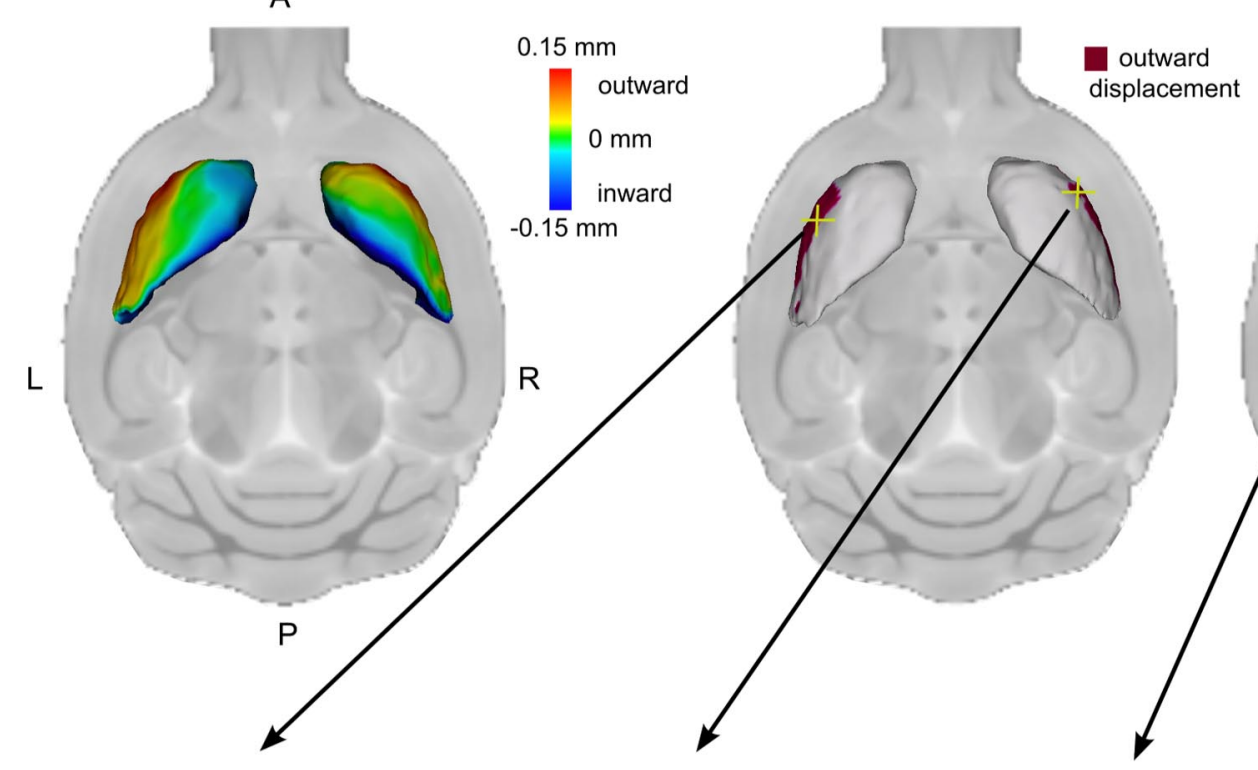

b

C

c

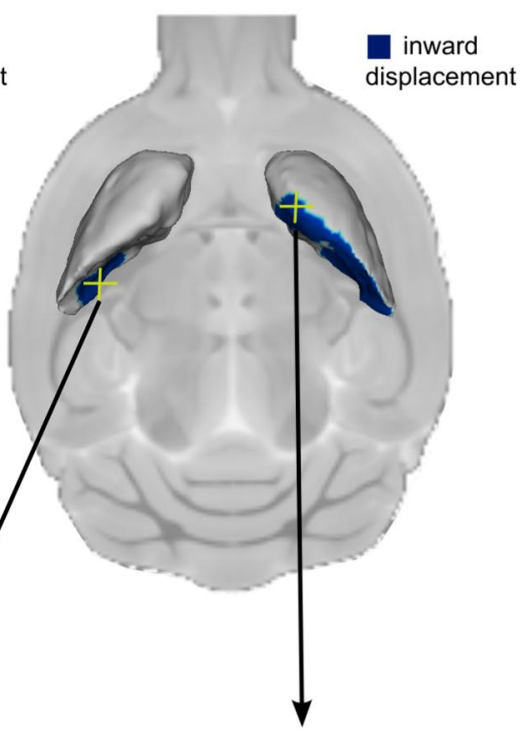

Figure 2. Striatum shape was altered by cocaine exposure. Group differences in striatum surface position show that the lateral surface of the striatum was displaced outward (away from the center of the structure) and the medial surface of the striatum was displaced inward (toward the center of the structure) in mice exposed to cocaine during adolescence relative to saline-exposed mice (a). Maps show surface points where there is an interaction between age and drug (right hemisphere, $t>2.35$; left hemisphere, $t>2.79 ; 5 \% \mathrm{FDR}$ ) and a difference between cocaine and saline exposure during adolescence (right hemisphere, $t>2.57$; left hemisphere, $t>2.79 ; 5 \% \mathrm{FDR}$ ) reflecting outward $(\boldsymbol{b})$ and inward (c) displacement of the striatum surface. A, Anterior; $P$, posterior; $\mathrm{L}$, left; $\mathrm{R}$, right. Surface position in the adolescent-exposed mice at selected highlighted vertices (yellow crosshairs) are displayed in the box plots below. In these box plots the midline represents the median of the data, the box shows the first and third quartiles, and the vertical line represents the range.

$0.01, t$ test (cocaine vs saline in adolescent-treated groups): $t_{(13)}=$ 8.86, $p<0.01)$ ], anterior cingulate cortex [Fig. 1d; two-way ANOVA: drug by age interaction $F_{(1,28)}=26.01, p<0.01 ; t$ test (cocaine vs saline in adolescent-treated groups): $t_{(13)}=5.81, p<$ $0.05)$ ], ventral pallidum [(Fig. 1e; two-way ANOVA: drug by age interaction $F_{(1,28)}=22.19, p<0.05 ; t$ test (cocaine vs saline in adolescent-treated groups): $\left.\left.t_{(13)}=5.02, p<0.05\right)\right]$, medial forebrain bundle [(Fig. 1f; two-way ANOVA: drug by age interaction $F_{(1,28)}=21.61, p<0.05 ; t$ test (cocaine vs saline in adolescenttreated groups): $\left.\left.t_{(13)}=5.74, p<0.05\right)\right]$, insular cortex [(Fig. $1 g$; two-way ANOVA: drug by age interaction $F_{(1,28)}=16.12, p<$ 0.05 ; $t$ test (cocaine vs saline in adolescent-treated groups): $t_{(13)}=$ $4.84, p<0.05)$ ], and cortical amygdaloid area [(Fig. $1 i$, two-way ANOVA: drug by age interaction $F_{(1,28)}=20.79, p<0.05 ; t$ test (cocaine vs saline in adolescent-treated groups): $t_{(13)}=6.19, p<$ $0.05)]$ in mice exposed to cocaine during adolescence compared with saline-exposed controls. Volumetric increases caused by cocaine were observed in the right orbitofrontal cortex [(Fig. 1a; two-way ANOVA: drug by age interaction $F_{(1,28)}=23.35, p<$ 0.05 ; $t$ test (cocaine vs saline in adolescent-treated groups): $t_{(13)}=$ 5.86, $p<0.05)$ ] and substantia nigra [(Fig. $1 j$; two-way ANOVA: drug by age interaction $F_{(1,28)}=19.10, p<0.05$; $t$ test (cocaine vs saline in adolescent-treated groups): $\left.\left.t_{(13)}=6.11, p<0.05\right)\right]$ in mice exposed during adolescence. Additionally there was both volumetric expansion and reduction in the striatum as a result of cocaine exposure in adolescent mice. The anterior dorsal striatum showed volumetric expansion [(Fig. 1b; two-way ANOVA drug by age interaction $F_{(1,28)}=20.89, p<0.05 ; t$ test (cocaine vs saline in adolescent-treated groups): $\left.\left.t_{(13)}=5.79, p<0.05\right)\right]$ while the posterior striatum showed volumetric reduction [(Fig. 1h; two-way ANOVA drug by age interaction $F_{(1,28)}=17.48, p<$ $0.05 ; t$ test (cocaine vs saline in adolescent-treated groups): $t_{(13)}=$ $5.18, p<0.05)$ ]. All $p$ values were adjusted to account for multiple comparisons with the FDR (with the FDR corrected value corresponding to the expected false positive rate). Beyond changes in these reward-related regions, significant changes were additionally observed in the anterior olfactory area, piriform cortex, corpus callosum, rhinal cortex, and medulla in mice treated with cocaine during adolescence (Table 1). We found no significant regional changes in volume following cocaine exposure during adulthood.

The local bidirectional changes in striatum volume suggest that cocaine exposure caused the shape of the striatum to change, and detailed striatal shape analysis supported this conclusion. The lateral surface of the striatum was displaced outward (i.e., away from the center of the structure) and the medial surface of the striatum was displaced inward (i.e., toward the center of the structure) bilaterally in adolescent cocaine-exposed mice relative to saline-exposed mice (Fig. 2a). For example, these shape alterations were reflected in significant changes in striatum surface position for points on the right lateral [(Fig. $2 b$; two-way ANOVA: drug by age interaction $F_{(1,28)}=3.18, p<0.05$; $t$ test (cocaine vs saline in adolescent-treated groups): $t_{(13)}=5.16, p<$ $0.05)$ ], left lateral [(Fig. 2b; two-way ANOVA: drug by age interac- 

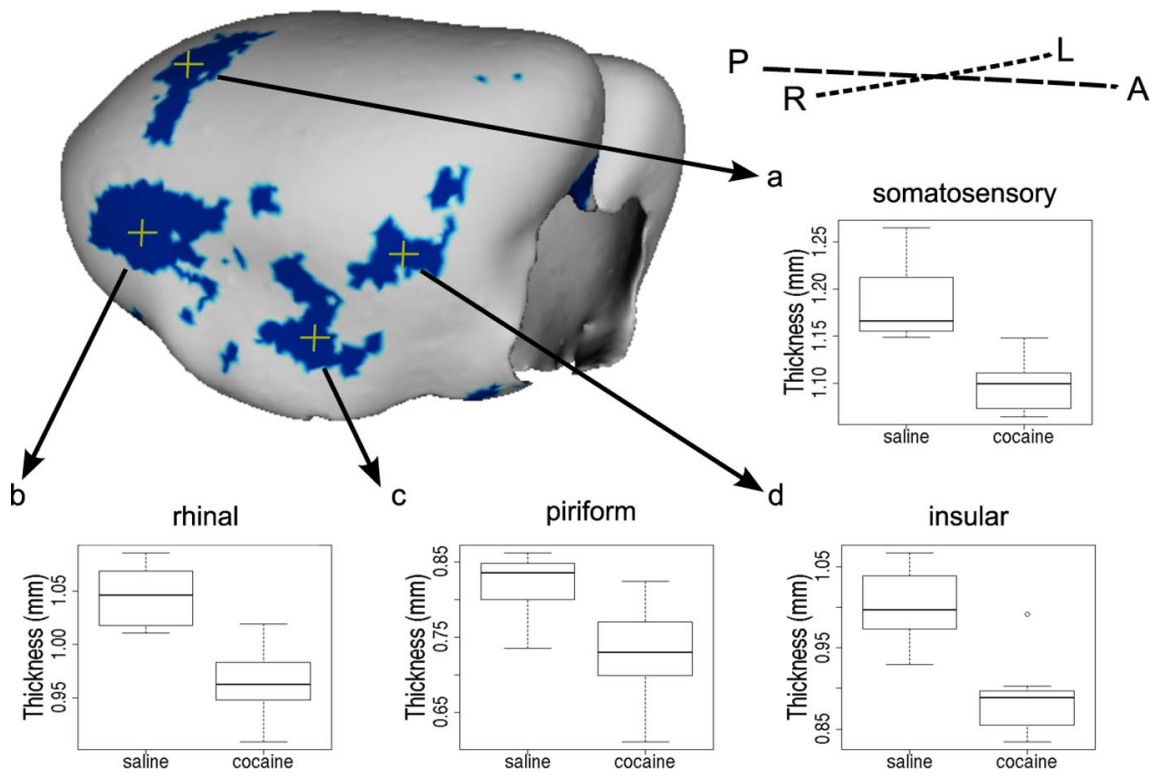

Figure 3. Cortical surface shows localization of cortical thinning in mice exposed to cocaine during adolescence. Blue color indicates vertices where there is an interaction between age and drug ( $t>2.6,10 \% \mathrm{FDR})$ and a difference between cocaine and saline exposure during adolescence $(t>2.6,10 \% \mathrm{FDR})$. The letters $A, P, L$ and $R$ refer to the anterior, posterior, left and right directions in the brain, respectively. Cortical thickness in the adolescent-exposed mice at selected highlighted vertices (yellow crosshairs) are displayed in the box plots $(\boldsymbol{a}-\boldsymbol{d})$ where the midline represents the median of the data, the box shows the first and third quartiles, and the vertical line represents the range.
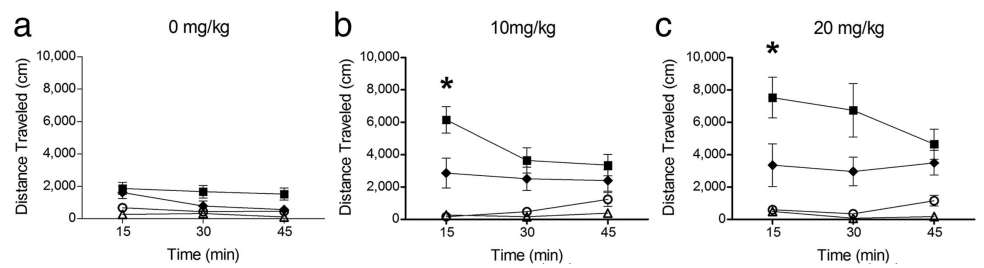

Figure 4. Locomotor sensitization in mice pre-exposed to cocaine during adolescence and adulthood. Distance traveled in response to challenge injections of $0 \mathrm{mg} / \mathrm{kg}(\boldsymbol{a}), 10 \mathrm{mg} / \mathrm{kg}(\boldsymbol{b})$, and $20 \mathrm{mg} / \mathrm{kg}(\boldsymbol{c})$ of cocaine following pre-exposure to cocaine or saline during adolescence or adulthood. Mice pre-exposed to cocaine during adolescence showed an enhanced response to 10 and $20 \mathrm{mg} / \mathrm{kg}$ doses of cocaine during the first $15 \mathrm{~min}$ of the test session compared with mice exposed to cocaine during adulthood $\left({ }^{*} p<0.05\right)$. Values are means \pm SEM.

tion $F_{(1,28)}=4.69, p<0.05 ; t$ test (cocaine vs saline in adolescenttreated groups): $\left.\left.t_{(13)}=4.97, p<0.05\right)\right]$, right medial [(Fig. $2 c$; two-way ANOVA: drug by age interaction $F_{(1,28)}=4.07, p<$ $0.01 ; t$ test (cocaine vs saline in adolescent-treated groups): $t_{(13)}=$ 6.37, $p<0.05)$ ], and left medial [(Fig. $2 c$; two-way ANOVA: drug by age interaction $F_{(1,28)}=3.50, p<0.05$; $t$ test (cocaine vs saline in adolescent-treated groups): $\left.\left.t_{(13)}=4.46, p<0.05\right)\right]$ surfaces of the striatum. All $p$ values were adjusted with the FDR.

In addition to these regional changes, we found that adolescent but not adult cocaine exposure produced cortical thinning that was significant in regions of the right hemisphere. These changes are consistent with the more pronounced voxel level differences in the right hemisphere, and supported by significant age of exposure by drug interactions in several cortical regions. For example, comparison of mice treated with saline and cocaine during adolescence revealed thinning of the cortex in the primary somatosensory cortex [(Fig. 3a; two-way ANOVA: drug by age interaction $F_{(1,28)}=3.83, p<0.05 ; t$ test (cocaine vs saline in adolescent-treated groups): $\left.t_{(13)}=4.55, p<0.10\right)$ ], the rhinal cortex [ Fig. $3 b$; two-way ANOVA: drug by age interaction $F_{(1,28)}=$ 4.73, $p<0.05 ; t$ test (cocaine vs saline in adolescent-treated
0 adolescent saline $\Delta$ adult saline adult cocaine

groups): $\left.\left.t_{(13)}=4.83, p<0.10\right)\right]$, the piriform cortex [(Fig. 3c; two-way ANOVA: drug by age interaction $F_{(1,28)}=3.49, p<$ 0.10 ; $t$ test (cocaine vs saline in adolescenttreated groups): $\left.t_{(13)}=3.06, p<0.10\right)$ ], and the insular cortex [(Fig. $3 d$; two-way ANOVA: drug by age interaction $F_{(1,28)}=$ 5.38, $p<0.05$; $t$ test (cocaine vs saline in adolescent-treated groups): $t_{(13)}=4.51$, $p<0.10)]$. All $p$ values were adjusted with the FDR.

\section{Behavioral sensitization}

We assessed the impact of adolescent and adult cocaine exposure on subsequent responses to cocaine using a cocaine sensitization paradigm (Robinson and Berridge, 1993). Following cocaine or saline pre-exposure and abstinence, all mice were challenged with an injection of saline $(0 \mathrm{mg} / \mathrm{kg})$, low-dose cocaine (10 mg/kg), and high-dose cocaine (20 $\mathrm{mg} / \mathrm{kg}$ ) before locomotor testing on successive days (Fig. 4). To assess the impact of cocaine exposure and age of cocaine exposure on sensitization we conducted three separate three-way ANOVAs for the test data for each challenge dose $(0,10$, and $20 \mathrm{mg} / \mathrm{kg}$ cocaine). For each three-way ANOVA, age at time of exposure (adolescence vs adult) and drug (cocaine vs saline) were between-subject factors and time $(0-15,16-30$, and $31-45 \mathrm{~min})$ was a within-subject factor.

In all three test sessions mice with a history of cocaine exposure exhibited altered levels of locomotion following challenge injections compared with those that had previously been exposed to only saline, and these effects depended on both age of exposure and test time (three-way ANOVA age $\times$ drug $\times$ time interaction: $0 \mathrm{mg} / \mathrm{kg}$ $F_{(2,52)}=3.24, p<0.05 ; 10 \mathrm{mg} / \mathrm{kg} F_{(2,52)}=10.60, p<0.001 ; 20$ $\left.\mathrm{mg} / \mathrm{kg} F_{(2,52)}=5.32, p<0.01\right)$. Mice with a history of cocaine exposure exhibited an enhanced locomotor response to an injection of saline, reflecting sensitization to the previously drugpaired environment (three-way ANOVA: main effect of drug $\left.F_{(1,26)}=14.72, p<0.001\right)$. Mice that had been pre-exposed to cocaine also exhibited an enhanced locomotor response following $10 \mathrm{mg} / \mathrm{kg}$ (three-way ANOVA: main effect of drug $F_{(1,26)}=$ $31.60, p<0.0001)$ and $20 \mathrm{mg} / \mathrm{kg}$ (three-way ANOVA: main effect of drug $\left.F_{(1,26)}=27.28, p<0.0001\right)$ cocaine, indicating sensitization to the locomotor stimulant effects of cocaine.

Exposure to cocaine during adolescence, but not adulthood, altered brain structure. Therefore we next evaluated whether mice pre-exposed to cocaine during adolescence showed an enhanced response to cocaine compared with the mice pre-exposed during adulthood. Since changes in locomotor activity were most pronounced in the first $15 \mathrm{~min}$, we focused on this test period. Strikingly, adolescence-exposed mice exhibited enhanced sensitization following the $10 \mathrm{mg} / \mathrm{kg}$ (two-way ANOVA: age $\times$ drug interaction $F_{(1,26)}=6.57, p<0.05$ ) and $20 \mathrm{mg} / \mathrm{kg}$ (two-way ANOVA: age $\times$ drug interaction $\left.F_{(1,26)}=4.18, p=0.051\right)$ co- 
caine challenge dose but not following the $0 \mathrm{mg} / \mathrm{kg}$ dose (two-way ANOVA: age $\times$ drug interaction $\left.F_{(1,26)}=1.13, p=0.81\right)$. Post hoc comparisons confirmed that locomotor activity was greater in mice exposed to cocaine during adolescence than during adulthood following the $10 \mathrm{mg} / \mathrm{kg}\left(t\right.$ test: $\left.t_{(14)}=2.7, p<0.05\right)$ and 20 $\mathrm{mg} / \mathrm{kg}\left(t\right.$ test: $\left.t_{(14)}=2.3, p<0.05\right)$ cocaine challenge dose.

\section{Discussion}

Using unbiased whole-brain analysis of high-resolution MR images in mice, we examined the impact of chronic cocaine exposure on brain structure. There were two main findings. First, cocaine exposure produced persistent structural alterations that were, in many cases, localized to brain regions involved in addiction, including the nucleus accumbens, striatum, medial forebrain bundle, ventral pallidum, substantia nigra, and orbitofrontal and insular cortices. Second, these changes were most pronounced in mice exposed to cocaine during adolescence. A recent study reported volumetric alterations in several gray matter regions including the striatum and insular cortex in human cocaine addicts and their nonstimulant-dependent siblings, suggesting that certain brain abnormalities precede drug use and predispose these individuals to addiction (Ersche et al., 2012). Our results further indicate that cocaine itself impacts the development of many of the same regions associated with drug dependence.

Perhaps the most striking finding was that many of the cocaineinduced structural abnormalities were identified in regions involved in mediating cocaine's acute and chronic effects that are associated with reward and sensitization. For example, the nucleus accumbens, medial forebrain bundle, and ventral pallidum were reduced in volume, consistent with cocaine's primary action on the mesolimbic dopaminergic pathway. Long-lasting neuroadaptation within this system likely contributes to locomotor sensitization (Vanderschuren and Pierce, 2010). Additionally, cocaine exposure led to a decrease in the volume of the anterior cingulate cortex and cortical amygdaloid area, regions where decreased metabolic activity has been associated with cocaine craving in human subjects (Childress et al., 1999). The insular cortex was likewise reduced in volume, and the structural alterations in the insular have previously been associated with dependence on cocaine (as well as other drugs of abuse) in human addicts (Franklin et al., 2002; Ersche et al., 2011; Gardini and Venneri, 2012). Following cocaine exposure the substantia nigra - a dopamine rich area of the midbrain - and the orbitofrontal cortex were increased in volume. Previous human imaging and rodent studies implicate orbital frontal dysfunction in cocaine addiction through its impact on conditioned reinforcement and drug craving (Everitt et al., 2007). Finally, we found volume and shape differences in the striatum following cocaine exposure in adolescent mice. Volume analysis revealed that cocaine exposure caused portions of the anterior dorsal striatum to increase in size and the posterior striatum to reduce in size, while shape analysis revealed lateral outward displacement and medial inward displacement of the striatum bilaterally as a result of cocaine exposure. These bidirectional changes may account for previous discrepant results from human imaging studies, with some reporting reduced (Barrós-Loscertales et al., 2011; Hanlon et al., 2011) and others increased (Jacobsen et al., 2001; Ersche et al., 2011) striatal volume in cocaine-dependent subjects. These results are consistent with an emerging literature suggesting that reorganization of circuitry within the striatum leads to loss of control of voluntary behavior, which is a hallmark of addiction (Everitt and Robbins, 2005). Therefore, together these analyses reveal that adolescent cocaine exposure impacts a network of regions that are directly innervated by dopaminergic neurons. This suggests that the vol- umetric changes may be mediated by the direct actions of cocaine in these regions, and raises the possibility that structural alterations in this network of regions might contribute to altered subsequent responding to drugs of abuse. However, it is important to note that not all regions innervated by dopaminergic neurons were impacted by adolescent cocaine exposure (e.g., medial prefrontal cortex). Moreover, there were volumetric alterations in regions that do not receive dopaminergic innervation. This latter observation indicates that chronic cocaine exposure additionally causes secondary and likely tertiary effects on brain morphology.

We used an MRI-based approach to systematically track cocaineinduced alterations in brain structure. These analyses provided information about the precise localization of cortical thickness and volume change within structures and revealed shifts in the overall shape of brain structures. What is responsible for these structural changes? Previous studies focusing on individual regions of the brain have shown that chronic cocaine increases spine number and dendritic branching in the nucleus accumbens and prefrontal cortex (Robinson and Kolb, 1999) and that astrocyte number increases following cocaine exposure and 3 weeks of abstinence in the nucleus accumbens (Bowers and Kalivas, 2003). Since we observed a decrease, rather than an increase, in accumbens volume here this suggests that factors other than neuronal morphology and gliosis must contribute to volumetric alterations. These factors may include altered axon sprouting, neurogenesis, fiber reorganization, myelin formation, and remodeling and angiogenesis (Zatorre et al., 2012). Most likely combinations of these factors interact to contribute to the changes in MR signal described here.

The effects of cocaine exposure on brain structure and locomotor sensitization were more pronounced during adolescence compared with young adulthood. Although adolescence is sometimes perceived to be a developmental phase that is unique to humans, all mammals undergo a similar transition from dependence to independence, and adolescence has been widely modeled in rodent studies (Adriani and Laviola, 2004). Cocaine use is often initiated during adolescence when the brain is still developing (Lenroot and Giedd, 2006; Blakemore, 2012). The adolescent brain has been characterized by an imbalance between an early developing subcortical striatal system that is sensitive to motivational stimuli and a late developing prefrontal cognitive control system (Casey and Jones, 2010). Given that the brain, and specifically its reward circuitry, is undergoing dramatic changes throughout adolescence, this might suggest that the adolescent brain is more vulnerable to drugs of abuse like cocaine. This is supported by epidemiological studies that show that when drug use is initiated during adolescence there are higher lifetime rates of drug use and faster progression to dependency than in people who begin in adulthood (Anthony and Petronis, 1995; Grant and Dawson, 1998; O'Brien and Anthony, 2005). Here we observed enhanced sensitization to the locomotor stimulant effects of cocaine following cocaine exposure during adolescence. These behavioral results parallel our structural analyses and indicate that cocaine exposure has a more pronounced impact on the developing brain. In our experiments the direct relationship between brain anatomy and behavior cannot be explored as the two outcomes were assessed in separate groups of mice. However, the absence of significant structural differences in the mice treated during adulthood suggests that forms of plasticity that are not associated with volumetric changes (e.g., modified strength and/or rearrangement of synapses) likely contribute to the observed behavioral sensitization following chronic cocaine exposure in these mice.

In human studies it is often challenging to isolate the effect of age of onset of drug use on brain structure while controlling for the total amount of drug exposure in an individual. By making 
cocaine exposure equivalent, our experiments indicate that an earlier age of onset is associated with more pronounced structural alterations in reward-related regions of the brain. These results also show that structural alterations seen in the brains of cocaine users can be caused by the drug and do not just reflect preexisting anatomical differences. These cocaine-induced effects may aggravate or interact with pre-existing abnormalities in brain structure leading to behaviors related to drug dependence.

\section{References}

Adriani W, Laviola G (2004) Windows of vulnerability to psychopathology and therapeutic strategy in the adolescent rodent model. Behav Pharmacol 15:341-352. CrossRef Medline

Anthony JC, Petronis KR (1995) Early-onset drug use and risk of later drug problems. Drug Alcohol Depend 40:9-15. CrossRef Medline

Avants BB, Epstein CL, Grossman M, Gee JC (2008) Symmetric diffeomorphic image registration with cross-correlation: evaluating automated labeling of elderly and neurodegenerative brain. Med Image Anal 12:26-41. CrossRef Medline

Barrós-Loscertales A, Garavan H, Bustamante JC, Ventura-Campos N, Llopis JJ, Belloch V, Parcet MA, Avila C (2011) Reduced striatal volume in cocaine-dependent patients. Neuroimage 56:1021-1026. CrossRef Medline

Bartzokis G, Beckson M, Lu PH, Edwards N, Rapoport R, Wiseman E, Bridge $P$ (2000) Age-related brain volume reductions in amphetamine and cocaine addicts and normal controls: implications for addiction research. Psychiatry Res 98:93-102. CrossRef Medline

Blakemore SJ (2012) Imaging brain development: the adolescent brain. Neuroimage 61:397-406. Medline

Bowers MS, Kalivas PW (2003) Forebrain astroglial plasticity is induced following withdrawal from repeated cocaine administration. Eur J Neurosci 17:1273-1278. CrossRef Medline

Casey BJ, Jones RM (2010) Neurobiology of the adolescent brain and behavior. J Am Acad Child Adolesc Psychiatry 49:1189-1201; quiz 1285. CrossRef Medline

Childress AR, Mozley PD, McElgin W, Fitzgerald J, Reivich M, O’Brien CP (1999) Limbic activation during cue-induced cocaine craving. Am J Psychiatry 156:11-18. Medline

Chung MK, Worsley KJ, Paus T, Cherif C, Collins DL, Giedd JN, Rapoport JL, Evans AC (2001) A unified statistical approach to deformation-based morphometry. Neuroimage 14:595-606. CrossRef Medline

Chung MK, Worsley KJ, Robbins S, Paus T, Taylor J, Giedd JN, Rapoport JL, Evans AC (2003) Deformation-based surface morphometry applied to gray matter deformation. Neuroimage 18:198-213. CrossRef Medline

Compton WM, Thomas YF, Stinson FS, Grant BF (2007) Prevalence, correlates, disability, and comorbidity of DSM-IV drug abuse and dependence in the United States: results from the national epidemiologic survey on alcohol and related conditions. Arch Gen Psychiatry 64:566-576. CrossRef Medline

Dorr AE, Lerch JP, Spring S, Kabani N, Henkelman RM (2008) High resolution three-dimensional brain atlas using an average magnetic resonance image of 40 adult C57 Bl/6J mice. Neuroimage 42:60-69. CrossRef Medline

Ersche KD, Barnes A, Jones PS, Morein-Zamir S, Robbins TW, Bullmore ET (2011) Abnormal structure of frontostriatal brain systems is associated with aspects of impulsivity and compulsivity in cocaine dependence. Brain 134:2013-2024. CrossRef Medline

Ersche KD, Jones PS, Williams GB, Turton AJ, Robbins TW, Bullmore ET (2012) Abnormal brain structure implicated in stimulant drug addiction. Science 335:601-604. CrossRef Medline

Everitt BJ, Robbins TW (2005) Neural systems of reinforcement for drug addiction: from actions to habits to compulsion. Nat Neurosci 8:1481-1489. CrossRef Medline

Everitt BJ, Hutcheson DM, Ersche KD, Pelloux Y, Dalley JW, Robbins TW (2007) The orbital prefrontal cortex and drug addiction in laboratory animals and humans. Ann N Y Acad Sci 1121:576-597. CrossRef Medline

Franklin TR, Acton PD, Maldjian JA, Gray JD, Croft JR, Dackis CA, O’Brien CP, Childress AR (2002) Decreased gray matter concentration in the insular, orbitofrontal, cingulate, and temporal cortices of cocaine patients. Biol Psychiatry 51:134-142. CrossRef Medline

Gardini S, Venneri A (2012) Reduced grey matter in the posterior insula as a structural vulnerability or diathesis to addiction. Brain Res Bull 87:205-211. CrossRef Medline

Gawin FH (1991) Cocaine addiction: psychology and neurophysiology. Science 251:1580-1586. CrossRef Medline

Genovese CR, Lazar NA, Nichols T (2002) Thresholding of statistical maps in functional neuroimaging using the false discovery rate. Neuroimage 15: 870 -878. CrossRef Medline

Giedd JN (2008) The teen brain: insights from neuroimaging. J Adolesc Health 42:335-343. CrossRef Medline

Grant BF, Dawson DA (1998) Age of onset of drug use and its association with DSM-IV drug abuse and dependence: results from the National Longitudinal Alcohol Epidemiologic Survey. J Subst Abuse 10:163-173. CrossRef Medline

Hanlon CA, Dufault DL, Wesley MJ, Porrino LJ (2011) Elevated gray and white matter densities in cocaine abstainers compared to current users. Psychopharmacology 218:681-692. CrossRef Medline

Jacobsen LK, Giedd JN, Gottschalk C, Kosten TR, Krystal JH (2001) Quantitative morphology of the caudate and putamen in patients with cocaine dependence. Am J Psychiatry 158:486-489. CrossRef Medline

Klein A, Andersson J, Ardekani BA, Ashburner J, Avants B, Chiang MC, Christensen GE, Collins DL, Gee J, Hellier P, Song JH, Jenkinson M, Lepage C, Rueckert D, Thompson P, Vercauteren T, Woods RP, Mann JJ, Parsey RV (2009) Evaluation of 14 nonlinear deformation algorithms applied to human brain MRI registration. Neuroimage 46:786-802. CrossRef Medline

Lenroot RK, Giedd JN (2006) Brain development in children and adolescents: insights from anatomical magnetic resonance imaging. Neurosci Biobehav Rev 30:718-729. CrossRef Medline

Leow AD, Yanovsky I, Chiang MC, Lee AD, Klunder AD, Lu A, Becker JT, Davies SW, Toga AW, Thompson PM (2007) Statistical properties of Jacobian maps and the realization of unbiased large-deformation nonlinear image registration. IEEE Trans Med Imaging 26:822-832. CrossRef Medline

Lerch JP, Carroll JB, Dorr A, Spring S, Evans AC, Hayden MR, Sled JG, Henkelman RM (2008a) Cortical thickness measured from MRI in the YAC128 mouse model of Huntington's disease. Neuroimage 41:243-251. CrossRef Medline

Lerch JP, Carroll JB, Spring S, Bertram LN, Schwab C, Hayden MR, Henkelman RM (2008b) Automated deformation analysis in the YAC128 Huntington disease mouse model. Neuroimage 39:32-39. CrossRef Medline

Lerch JP, Sled JG, Henkelman RM (2011) MRI phenotyping of genetically altered mice. Methods Mol Biol 711:349-361. CrossRef Medline

Makris N, Gasic GP, Kennedy DN, Hodge SM, Kaiser JR, Lee MJ, Kim BW, Blood AJ, Evins AE, Seidman LJ, Iosifescu DV, Lee S, Baxter C, Perlis RH, Smoller JW, Fava M, Breiter HC (2008) Cortical thickness abnormalities in cocaine addiction-a reflection of both drug use and a pre-existing disposition to drug abuse? Neuron 60:174-188. CrossRef Medline

Nestler EJ (2005) The neurobiology of cocaine addiction. Sci Pract Perspect 3:4-10. CrossRef Medline

Nieman BJ, Bishop J, Dazai J, Bock NA, Lerch JP, Feintuch A, Chen XJ, Sled JG, Henkelman RM (2007) Review Article MR technology for biological studies in mice. NMR Biomed 20:291-303. CrossRef Medline

O’Brien MS, Anthony JC (2005) Risk of becoming cocaine dependent: epidemiological estimates for the United States, 2000-2001. Neuropsychopharmacology 30:1006-1018. CrossRef Medline

Pulipparacharuvil S, Renthal W, Hale CF, Taniguchi M, Xiao G, Kumar A, Russo SJ, Sikder D, Dewey CM, Davis MM, Greengard P, Nairn AC, Nestler EJ, Cowan CW (2008) Cocaine regulates MEF2 to control synaptic and behavioral plasticity. Neuron 59:621-633. CrossRef Medline

Robinson TE, Berridge KC (1993) The neural basis of drug craving: an incentive sensitization theory of drug addiction. Brain Res Brain Res Rev 18:247-291. CrossRef Medline

Robinson TE, Kolb B (1999) Alterations in the morphology of dendrites and dendritic spines in the nucleus accumbens and prefrontal cortex following repeated treatment with amphetamine or cocaine. Eur J Neurosci 11:1598-1604. CrossRef Medline

Robinson TE, Kolb B (2004) Structural plasticity associated with exposure to drugs of abuse. Neuropharmacology 47[Suppl 1]:33-46. CrossRef Medline

Sim ME, Lyoo IK, Streeter CC, Covell J, Sarid-Segal O, Ciraulo DA, Kim MJ, Kaufman MJ, Yurgelun-Todd DA, Renshaw PF (2007) Cerebellar gray matter volume correlates with duration of cocaine use in cocaine- 
dependent subjects. Neuropsychopharmacology 32:2229-2237. CrossRef Medline

Spear LP (2000) The adolescent brain and age-related behavioral manifestations. Neurosci Biobehav Rev 24:417-463. CrossRef Medline

Swendsen J, Conway KP, Degenhardt L, Glantz M, Jin R, Merikangas KR, Sampson N, Kessler RC (2010) Mental disorders as risk factors for substance use, abuse and dependence: results from the 10-year follow-up of the National Comorbidity Survey. Addiction 105:1117-1128. CrossRef Medline
Thomas MJ, Kalivas PW, Shaham Y (2008) Neuroplasticity in the mesolimbic dopamine system and cocaine addiction. Br J Pharmacol 154:327-342. Medline

Vanderschuren LJ, Pierce RC (2010) Sensitization processes in drug addiction. Curr Top Behav Neurosci 3:179-195. CrossRef Medline

Zatorre RJ, Fields RD, Johansen-Berg H (2012) Plasticity in gray and white: neuroimaging changes in brain structure during learning. Nat Neurosci 15:528-536. CrossRef Medline 